University of Nebraska - Lincoln

DigitalCommons@University of Nebraska - Lincoln

$2-2009$

\title{
Olanzapine and Risperidone Disrupt Conditioned Avoidance Responding in Phencyclidine-Pretreated or Amphetamine- Pretreated Rats by Selectively Weakening Motivational Salience of Conditioned Stimulus
}

\author{
Ming Li \\ University of Nebraska-Lincoln, mli2@unl.edu \\ Wei He \\ University of Nebraska-Lincoln \\ Alexa Mead \\ University of Nebraska-Lincoln
}

Follow this and additional works at: https://digitalcommons.unl.edu/psychfacpub

Part of the Psychiatry and Psychology Commons

Li, Ming; He, Wei; and Mead, Alexa, "Olanzapine and Risperidone Disrupt Conditioned Avoidance Responding in Phencyclidine-Pretreated or Amphetamine-Pretreated Rats by Selectively Weakening Motivational Salience of Conditioned Stimulus" (2009). Faculty Publications, Department of Psychology. 413.

https://digitalcommons.unl.edu/psychfacpub/413

This Article is brought to you for free and open access by the Psychology, Department of at DigitalCommons@University of Nebraska - Lincoln. It has been accepted for inclusion in Faculty Publications, Department of Psychology by an authorized administrator of DigitalCommons@University of Nebraska - Lincoln. 
Published in Behavioural Pharmacology 20(1) (February 2009): 84-98. Copyright 2009, Wolters Kluwer Health/Lippincott, Williams \& Wilkins. Used by permission. DOI: 10.1097/FBP.0b013e3283243008.

Original Article

\title{
Olanzapine and Risperidone Disrupt Conditioned Avoidance Responding in Phencyclidine-Pretreated or Amphetamine-Pretreated Rats by Selectively Weak- ening Motivational Salience of Conditioned Stimulus
}

\author{
Ming Li, Wei He and Alexa Mead \\ Department of Psychology, University of Nebraska-Lincoln, Lincoln, Nebraska, USA \\ Correspondence to Assistant Professor Ming Li, PhD, E-mail: mli2@unl.edu.
}

Keywords: amphetamine sensitization, conditioned avoidance response, motivational salience, olanzapine, phencyclidine sensitization, rat, risperidone

Received August 29, 2008; accepted as revised November 25, 2008.

The rat conditioned avoidance response model is a well-established preclinical behavioral model predictive of antipsychotic efficacy. All clinically approved antipsychotic drugs disrupt conditioned avoidance responding - a feature that distinguishes them from other psychotherapeutics. We previously showed that the typical antipsychotic drug haloperidol disrupts avoidance responding by progressively attenuating the motivational salience of the conditioned stimulus (CS) in normal rats. In this study, using two pharmacological rat models of schizophrenia [e.g. phencyclidine (PCP) or amphetamine sensitization], we examined whether atypicals such as olanzapine or risperidone disrupt avoidance responding through the same behavioral mechanism. Rats were first pretreated with PCP, amphetamine, or saline under one of two different injection schedules for either 1 or 3 weeks. They were then trained to acquire avoidance responding to two types of CS (CS1 and CS2) that differed in their ability to predict the occurrence of the unconditioned stimulus. Finally, rats were tested repeatedly under olanzapine $(1.0 \mathrm{mg} / \mathrm{kg}$, subcutaneously) or risperidone $(0.33 \mathrm{mg} / \mathrm{kg}$, subcutaneously) daily for 5 or 7 consecutive days. We found that repeated olanzapine or risperidone treatment produced a progressive across-session decline in avoidance responding to both CS1 and CS2. Olanzapine and risperidone disrupted the CS2 (a less salient CS) avoidance to a greater extent than the CS1 avoidance. Pretreatment with PCP and amphetamine did not affect the disruptive effect of olanzapine or risperidone on avoidance responding. On the basis of these findings, we suggest that the atypical drugs olanzapine and risperidone, like the typical drug haloperidol, also disrupt avoidance responding primarily by attenuating the motivational salience of the CS.

\section{Introduction}

The rat conditioned avoidance response (CAR) is an aversively motivated conditioned instrumental response in which animals are trained to make an active motor response to avoid footshock. In a typical CAR experiment, a rat is placed in a two-compartment shuttle box and presented with a conditioned stimulus (CS, e.g. white noise), followed by an aversive unconditioned stimulus (US, e.g. footshock). After several CS-US pairings, the rat typically runs from one compartment to another during the CS (before the onset of the US), hence, avoiding the US.

In behavioral pharmacology, the rat CAR model is commonly used as a preclinical test for antipsychotic efficacy (Arnt, 1982). It is generally found that rats treated with low doses (noncataleptic) of antipsychotic drugs (APDs) fail to acquire or perform avoidance responses to the CS, whereas their escape responses to the US are not affected (Ader and
Clink, 1957; Wadenberg and Hicks, 1999). This selective disruption of avoidance but not escape most likely reflects the interactions between the characteristic pharmacological properties of antipsychotics and experimental factors related to differences in scheduling of events and patterns of behavioral responding (Spealman et al., 1983; Barrett, 2002; McMillan and Katz, 2002). Regardless of the nature of this selective disruption on avoidance responding, this feature has been effectively used to differentiate APDs from other classes of psychotropic drugs (e.g. anxiolytics and antidepressants, which lack this selectivity on avoidance vs. escape responses); to predict clinical potencies of APDs (potencies in the CAR test correlate with clinical potencies); and to identify potential APDs (Janssen et al., 1965; Bignami, 1978; Cook and Davidson, 1978; Kuribara and Tadokoro, 1981; Arnt, 1982; Van der Heyden and Bradford, 1988; Shannon et al., 1999; Wadenberg and Hicks, 1999). Therefore, understanding the nature of APD-induced avoidance decreases may shed light on the behavioral mechanism of antipsychotic action in the treatment of psychosis in patients with schizophrenia. 
We recently used the CAR model based on a repeated treatment regimen and examined the behavioral mechanisms of antipsychotic action in this model (Li et al., 2007). We found that rats treated with haloperidol (HAL) and tested daily for 7 consecutive days showed a progressive across-session decline in avoidance responding, suggesting that HAL may disrupt avoidance responding by progressively attenuating the motivational salience of the CS (Wise, 2004). We also found that HAL-treated rats tested under a 40-trial testing session showed a faster decline than those tested under a 10-trial session, which in turn showed a faster decline than those tested under a 3-trial session. These data, together with our early study showing that rats previously treated with HAL still exhibit decreased avoidance behavior in the later drug-free tests (Li et al., 2004), are suggested to reflect the weakening effect of the drug on the motivational salience of the CS. On the basis of these findings, we proposed that one possible mechanism by which APDs disrupt avoidance responding is to decrease the motivational salience of the CS or incentive motivation of rats to respond to the CS.

As the experiments described above were done primarily by using the typical antipsychotic HAL, whether the same behavioral mechanism is also responsible for the effects of atypical antipsychotics, such as olanzapine (OLZ) or risperidone (RIS), has not been tested and is still unknown. Because of the unique receptor-binding profile associated with each APD (Kapur and Remington, 2001), it is possible that they may work differently than HAL in the CAR model. Furthermore, subjects used in that study were normal rats, while antipsychotics are usually used to treat patients with schizophrenia. Whether antipsychotics work in the same way in putative rat models of schizophrenia has not been investigated. There is a possibility that these two functionally different populations might respond differently to antipsychotic treatment in the CAR model. Therefore, the primary goal of this study was to investigate the behavioral mechanism underlying the decrease in avoidance responding effect of OLZ and RIS in putative animal models of schizophrenia. Specifically, we sought to determine (i) whether OLZ and RIS, the two most widely prescribed atypical antipsychotics at the therapeutic relevant doses [approximately $65-80 \%$ striatal D2 occupancy in rodents (Kapur et al., 2003)], produce a similar progressive across-session decline in avoidance responding in putative rat models of schizophrenia [e.g. amphetamine (AMPH) pretreated or phencyclidine (PCP) pretreated]; and (ii) to what extent repeated OLZ and RIS treatment suppresses avoidance responding by attenuating motivational salience of the CS in the CAR model.

We chose AMPH-pretreated or PCP-pretreated rats as animal models of schizophrenia because they mimic many aspects of the illness at multiple levels, such as hyperdopaminergic (Robinson and Becker, 1986) and hypoglutamatergic activity (Jentsch and Roth, 1999), prepulse inhibition deficit (Geyer et al., 2001; Russig et al., 2003), latent inhibition deficit (Tenn et al., 2003), hypofrontal function and attentional set-shifting deficit (Fletcher et al., 2005; Tenn et al., 2005), and social interaction deficit (Sams-Dodd, 1998b). To explore the possible motivational salience attenuation mechanism, we used a modified avoidance conditioning procedure involving two types of CS (CS1 and CS2) that varied in their salience and ability to predict the occurrence of the US. If OLZ and RIS disrupt avoidance responding by selectively attenuating the motivational salience of the CS, we expected that both drugs would have a stronger disruptive effect on a less salient CS (CS2)-elicited avoidance than a highly salient CS (CS1)-elicited one.

\section{Methods}

Subjects

Male Sprague-Dawley rats (226-250 g upon arrival, Charles River, Portage, Michigan, USA) were housed two per cage, in $48.3 \times 26.7 \times 20.3 \mathrm{~cm}$ transparent polycarbonate cages under 12-h light/dark conditions (light on between 06.30 and $18.30 \mathrm{~h}$ ). Room temperature was Maintained at 21 $\pm 11^{\circ} \mathrm{C}$ with a relative humidity of $55-60 \%$. Food and water were freely available. Animals were allowed at least 1 week of habituation to the animal facility before being used in experiments. All procedures were approved by the Institutional Animal Care and Use Committee at the University of Nebraska-Lincoln.

\section{Avoidance conditioning apparatus}

Six identical two-way shuttle boxes custom designed and manufactured by Med Associates (St. Albans, Vermont, USA) were used. Each box was housed in a ventilated, sound-insulated isolation cubicle $(96.52 \mathrm{~cm}$ wide $\times 35.56$ $\mathrm{cm}$ deep $\times 63.5 \mathrm{~cm}$ high). Each box was $64 \mathrm{~cm}$ long, $30 \mathrm{~cm}$ high (from grid floor), and $24 \mathrm{~cm}$ wide, and was divided into two equal-sized compartments by a partition with an arch style doorway $(15 \mathrm{~cm}$ high $\times 9 \mathrm{~cm}$ wide at base $)$. A barrier ( $4 \mathrm{~cm}$ high) was placed between the two compartments, and therefore the rats had to jump from one compartment to the other. The grid floor consisted of 40 stainless-steel rods with a diameter of $0.48 \mathrm{~cm}$, spaced $1.6 \mathrm{~cm}$ apart center to center, through which a scrambled footshock (US, $0.8 \mathrm{~mA}$; maximum duration: $5 \mathrm{~s}$ ) was delivered by a constant current shock generator (Model ENV-410B) and scrambler (Model ENV-412). Illumination was provided by two houselights mounted at the top of each compartment. The CSs [either a $76 \mathrm{~dB}$ white noise (CS1) or a $85 \mathrm{~dB} 2800 \mathrm{~Hz}$ pure tone (CS2)] were produced by a speaker (ENV-224 AMX) mounted on the ceiling of the cubicle, centered above the shuttle box. Background noise (approximately $74 \mathrm{~dB}$ ) was provided by a ventilation fan affixed at the top corner of each isolation cubicle. All training and testing procedures were controlled by Med Associates programs running on a computer. 


\section{Locomotor activity apparatus}

Sixteen activity boxes were housed in a quiet room. The boxes were $48.3 \times 26.7 \times 20.3 \mathrm{~cm}$ transparent polycarbonate cages, which were similar to the home cages but were each equipped with a row of six photocell beams $(7.8 \mathrm{~cm}$ between two adjacent photobeams) placed $3.2 \mathrm{~cm}$ above the floor of the cage. A computer detected the disruption of the photocell beams and recorded the number of beam breaks. All experiments were run during the light cycle.

\section{Experiment 1: Effect of repeated OLZ treatment on CS1 and CS2 avoidance in PCP-pretreated rats}

Forty-two rats were injected with PCP $[\mathrm{n}=22,5 \mathrm{mg} / \mathrm{kg}$ intraperitoneally (i.p.)] or vehicle $(\mathrm{VEH})(\mathrm{n}=20)$ twice daily for 7 days. The two injections were separated by $12 \mathrm{~h}$. This PCP sensitization regimen has been widely used and is shown to induce a decrease in prefrontal dopaminergic utilization, augmented motor activity, and various cognitive deficits (Jentsch et al., 1997; Jentsch and Taylor, 2001; Rodefer et al., 2005; Dunn and Killcross, 2006). After a 5-day period of withdrawal (the drug-free period), rats were habituated to the shuttle box for 2 days (30 min/day). Rats were then trained daily in a modified two-way avoidance conditioning task for a total of 10 sessions. Each training session consisted of 30 trials. Twenty trials (CS1 trials) used a $10 \mathrm{~s} 76 \mathrm{~dB}$ white noise as the CS with its termination immediately followed by the shock ( $0.8 \mathrm{~mA}$; maximum duration: $5 \mathrm{~s}$ ) if the rats did not make an avoidance response; thus, it was a highly salient and perfect predictor of the US. The remaining 10 trials (CS2 trials) used a pure tone $(10 \mathrm{~s}, 2800 \mathrm{kHz}, 85 \mathrm{~dB})$ as the CS. In half of the CS2 trials (five trials), the CS2 was followed by the shock if the rat failed to respond to the CS2; whereas, in the other half, it was not; thus, it was a less salient and less informative signal compared with the CS1. The 20 CS1 trials were randomly intermixed with the 10 CS2 trials. During each trial, if a subject moved from one compartment into the other within the $10 \mathrm{~s}$ of CS presentation, the CS was immediately terminated and the shock was prevented, and this shuttling response was recorded as avoidance (termed CS1 avoidance or CS2 avoidance). If the rat remained in the same compartment for more than $10 \mathrm{~s}$ and made a crossing upon receiving the footshock, this response was recorded as escape. If the rat did not respond during the entire $5 \mathrm{~s}$ presentation of the shock, the trial was terminated and escape failure was recorded.

After training, 16 rats from the PCP group and 14 from the VEH group had achieved a high level of avoidance responding ( $\geq 14$ CS1 avoidances and at least one CS2 avoidance in the last two training sessions). Each group was then randomly assigned to two subgroups and underwent 7 consecutive days of repeated OLZ or VEH testing. This resulted in four experimental groups: PCP-VEH $(n=8)$, PCP-OLZ $(n=$ $8)$, VEH-VEH $(n=7)$, and VEH-OLZ $(n=7)$. On each test day, rats were injected with OLZ $(1.0 \mathrm{mg} / \mathrm{kg})$ or VEH (sterile water) subcutaneously (s.c.) $1 \mathrm{~h}$ before testing. The same procedure used during training was used for the drug testing.
Experiment 2: Effect of repeated OLZ treatment on CS1 and CS2 avoidance in AMPH-pretreated rats

We adopted a widely used AMPH treatment schedule that is shown to be effective in inducing deficits in prepulse inhibition or latent inhibition resembling those observed in patients with schizophrenia (Murphy et al., 2001; Pezze et al., 2002; Russig et al., 2002; Peleg-Raibstein et al., 2006; PelegRaibstein and Feldon, 2008). Forty-two rats received three daily i.p. injections of either $d$-amphetamine sulfate $(n=22$, AMPH at $1-5 \mathrm{mg} / \mathrm{ml} / \mathrm{kg})$ or $0.9 \%$ saline $(n=20$, saline at $1 \mathrm{ml} / \mathrm{kg}$ ). Injections were administered at 07.00, 13.00, and $19.00 \mathrm{~h}$ over a 6 -day period. On day 1 , the three AMPH injection doses were 1,2 , and $3 \mathrm{mg} / \mathrm{kg}$ in this escalating order. On day 2, the first AMPH injection dose was $4.0 \mathrm{mg} / \mathrm{kg}$, and the remaining two were $5.0 \mathrm{mg} / \mathrm{kg}$. From days 3-6, each AMPH injection dose was always $5.0 \mathrm{mg} / \mathrm{kg}$. The saline injection volume was always $1 \mathrm{ml} / \mathrm{kg}$.

The remainder of the experiment was similar to experiment 1. First, rats were trained to acquire avoidance responding to the CS1 and CS2. At the end of the training phase, only 12 AMPH-treated rats and 10 saline-treated rats had reached the training criterion ( $\geq 14$ CS1 avoidances and at least one CS2 avoidance in the last two training sessions). Thus, we gave all rats one additional training session to boost their performance. They were then randomly assigned to two subgroups and subjected to 7 days of OLZ tests. Four experimental groups were formed on the basis of pre-drug treatment (AMPH vs. VEH) and antipsychotic treatment (OLZ vs. VEH): AMPH-VEH $(n=4)$, AMPH-OLZ $(n=8)$, VEH-VEH $(n=4)$, and VEH-OLZ $(n=6)$. During each daily test, rats were injected with OLZ $(1.0 \mathrm{mg} / \mathrm{kg})$ or $\mathrm{VEH}$ (sterile water) s.c. $1 \mathrm{~h}$ before testing. The same procedure used during training was used for the drug testing.

\section{Experiment 3: Replication study of the effect of repeated OLZ treatment on CS1 and CS2 avoidance in AMPH-pre- treated rats}

In experiment 2, only 22 rats out of 42 (52\%) reached the training criterion, which was much lower compared with the 30 rats from experiment 1 (71\%). Our past experience suggests that under most circumstances, approximately $70-75 \%$ of rats trained in this task reach this criterion; thus, the lower percentage of rats reaching the training criterion might suggest that rats in experiment 2 did not adequately represent a valid sample of the rat population under study. Consequently, in experiment 3 , we tried to replicate experiment 2 using a new batch of rats. The basic procedure was identical to that of experiment 2 except that rats were only tested for four OLZ sessions, instead of seven, because we noticed that after four OLZ sessions, avoidance responding generally reached a minimum. In this experiment, 28 rats out of $42(67 \%)$ eventually reached the training criterion ( $\geq 14$ CS1 avoidances and at least one CS2 avoidance in the last two training sessions), and their grouping information was as follows: AMPH-VEH $(n=8)$, AMPH-OLZ $(n=8)$, VEH-VEH $(n=7)$, and VEH-OLZ $(n=5)$. 


\section{Experiment 4: Effect of repeated RIS and OLZ treatment on CS1 and CS2 avoidance in PCP-pretreated and AMPH-pre- treated rats}

In experiment 4, we used different PCP and AMPH treatment regimens to examine effects of repeated RIS and OLZ treatment on CS1 and CS2 avoidance in both PCP-pretreated and AMPH-pretreated rats. This experiment was done not only to replicate the findings from the above three experiments, but also to examine the generalization issue to ensure that they can be extended to other PCP and AMPH models of schizophrenia. As PCP and AMPH pretreatments were done in the same batch of rats, this experiment also allowed us to directly compare any possible differential effect of PCP or AMPH pretreatment on RIS-induced and OLZ-induced decrease in avoidance responding. Sixty rats were randomly assigned to one of three groups $(n=20)$, with each rat receiving an s.c. injection of d-amphetamine sulfate $(1.0-3.0 \mathrm{mg} /$ $\mathrm{kg}), \mathrm{PCP}(3.0 \mathrm{mg} / \mathrm{kg})$, or $0.9 \%$ saline $(1.0 \mathrm{ml} / \mathrm{kg})$ three times per week for 3 weeks for a total of nine injections. The AMPH dose increased from $1.0-3.0 \mathrm{mg} / \mathrm{kg}$, at the rate of $1 \mathrm{mg} / \mathrm{kg}$ each week. The PCP dose remained at $3.0 \mathrm{mg} / \mathrm{kg}$ throughout. This sensitization schedule for PCP and AMPH has been used by Tenn et al. (2005) who showed that it can produce a strong PCP and AMPH sensitization effect and that AMPH sensitization induces prepulse inhibition and latent inhibition deficits. After 18 days withdrawal from PCP and AMPH pretreatment, we assessed the AMPH and PCP pretreatment effect (e.g. behavioral sensitization effect). All rats were habituated to the locomotor activity apparatus for $30 \mathrm{~min} /$ day for 2 consecutive days. On day 3, rats were placed in the locomotor activity apparatus for $10 \mathrm{~min}$, and then they were taken out and injected with either AMPH at $0.5 \mathrm{mg} / \mathrm{kg}$ or PCP at $1.5 \mathrm{mg} / \mathrm{kg}$ and immediately placed back into the apparatus for another $60 \mathrm{~min}$. Half of the rats from each group $(n=10)$ were injected with AMPH, whereas the other half $(n=10)$ were injected with PCP. Locomotor activity (number of photobeam breaks) was measured in 5 min blocks for the entire 60-min testing session. One day later, the training phase consisting of 10 sessions started. The basic procedure was the same as described in the first three experiments with one slight modification. Halfway through the training phase (after the fifth session), we removed the eight rats which had the lowest avoidance responses on that day (one from PCP, five from the AMPH group, and two from the VEH group) from further training to eliminate unnecessary pain and stress, because they would most likely not reach the training criterion based on our experience. On the last (10th) training day, because of an unknown technical issue, data from eight rats were lost, and we thus used the data from the eighth and ninth training sessions to identify those that reached the training criterion ( $\geq 14$ CS1 avoidances and at least one CS2 avoidance in the last two training sessions). Forty-five rats (75\% of a total of 60 rats) were identified and were repeatedly tested daily for 7 days under either RIS or VEH. The following six experimental groups were formed: PCP-VEH $(n=$ 8), PCP-RIS $(n=8)$, AMPH-VEH $(n=7)$, AMPH-RIS $(n=6)$, VEH-VEH $(n=8)$, and VEH-RIS $(n=8)$. During each daily test, rats received an s.c. injection of either RIS $(0.33 \mathrm{mg} / \mathrm{kg})$ or $0.9 \%$ saline $1 \mathrm{~h}$ before testing. One day after the end of the seventh test, the previous three VEH groups were switched to OLZ $(1.0 \mathrm{mg} / \mathrm{kg})$ and further tested for another five sessions. This add-on experiment was intended to assess further the effect of PCP and AMPH pretreatment on the effect of OLZ.

Drugs

The injection solutions of $d$-amphetamine sulfate (AMPH, Sigma-RBI, Natick, Massachusetts, USA) and phencyclidine hydrochloride (PCP; gift from the National Institute on Drug Abuse Chemical Synthesis and Drug Supply Program and Sigma-Aldrich, St. Louis, Missouri, USA) were obtained by mixing drugs with $0.9 \%$ saline. OLZ (Toronto Research Chemical Inc., North York, Canada) and RIS (gift from NIMH Chemical Synthesis and Drug Supply Program) were dissolved in $1.5 \%$ glacial acetic acid in distilled water. We chose OLZ at $1.0 \mathrm{mg} / \mathrm{kg}$ and RIS at $0.33 \mathrm{mg} / \mathrm{kg}$ because they are effective in producing a progressive across-session decrease in avoidance responding in normal rats ( $\mathrm{Li}$ et al., 2007), and both drugs at these doses give rise to clinically comparable levels of striatal $\mathrm{D}_{2}$ occupancy (60-70\%) (Kapur et al., 2003).

\section{Statistical analysis}

CS1 and CS2 avoidance response data from the training phase were expressed as mean values \pm SEM and were analyzed using a factorial repeated-measures analysis of variance (ANOVA) with the between-subjects factor being 'pretreatment' (PCP, AMPH, or VEH) treatment condition and the within-subject factors being the test sessions ('session') and types of trials (e.g. 'type': CS1 avoidance or CS2 avoidance).

Each rat's avoidance performance on each drug test session was expressed as the percent avoidance relative to its own value on the last training (10th) day (except in experiment 4, where data from the 9 th training day were used for all rats) to account better for the differences in CS1 (maximum: 20 trials) and CS2 (maximum: 10) avoidances at the baseline. Data were analyzed using a factorial repeated-measures ANOVA with the between-subjects factors being 'pretreatment' (PCP, $\mathrm{AMPH}$, or VEH) and 'drug' treatment condition (OLZ, RIS, or $\mathrm{VEH}$ ) and the within-subject factors being the test sessions ('session') and types of trials (e.g. 'type': CS1 avoidance or CS2 avoidance). Two-group comparisons were tested using post-hoc Tukey tests. A conventional two-tailed level of significance at the $5 \%$ level was required.

For the locomotor activity data from experiment 4 , the number of photobeam breaks was expressed as mean values \pm SEM and analyzed using repeated-measures ANOVA with the pretreatment condition (PCP, AMPH, or VEH) and the challenge drugs (PCP or AMPH) as the between-subjects factors and the 5-min time block ('block') as the within-subjects factor. Two-group comparison was done using independent samples $t$-tests. 


\section{Results}

Experiment 1: Effect of repeated OLZ treatment on CS1 and CS2 avoidance in PCP-pretreated rats

One rat from the VEH group died before the completion of training. Its data were excluded from further analysis. Throughout the 10 training sessions, rats from both groups (PCP-pretreated or VEH-pretreated) showed a similar learning effect, as evidenced by the progressive increase in the number of CS1 and CS2 avoidance responses across sessions (data not shown). Repeated-measures ANOVA indicates that there were significant main effects of 'session' $\left[F_{(9,351)}=28.80\right.$, $P<0.001]$ and 'type' $\left[F_{(1,39)}=200.90, P<0.001\right]$, but no significant main effect of 'pretreatment' $\left[F_{(1,39)}=0.123, \mathrm{NS}\right]$ or 'type' $x$ 'pretreatment' and 'session' $\times$ 'pretreatment' interactions (all $P$ values $>0.75$ ). The acquisition of CS1 avoidance was faster than the acquisition of CS2 avoidance ['type' $\times$ 'session' interaction, $\left.F_{(9,351)}=13.01, P<0.001\right]$, a result that was expected from the experimental design in which only half of the CS2 trials were followed by shock, whereas all the CS1 trials were followed by shock if the rats failed to respond. Table 1 summarizes the mean numbers and percentages of avoidance response to CS1 and CS2 on the last training session for rats that reached the training criterion. No significant group difference on these measures was found (all $P$ values $>0.05)$.

During the OLZ testing phase, the VEH-treated rats maintained their training levels of CS1 and CS2 avoidance throughout the sessions, whereas the OLZ rats showed a pro- gressive decline in both CS1 and CS2 avoidances. Repeatedmeasures ANOVA indicated that there were significant main effects of 'session' $\left[F_{(6,156)}=6.34, P<0.001\right]$ and 'drug' $\left[F_{(1,26)}=\right.$ $82.12, P<0.001]$, and a significant 'session' $\times$ 'drug' interaction $\left[F_{(6,156)}=5.10, P<0.001\right]$. In addition, it seems that OLZ had a stronger disruptive effect on the CS2 avoidance than CS1 avoidance as it caused a sharper decline in the CS2 avoidance than the CS1 avoidance relative to the baseline (Figure 1). Statistical analysis confirmed this observation. There was a significant effect of 'type' $\times$ 'drug' interaction $\left[F_{(1,26)}=6.65\right.$, $P<0.02]$. Pretreatment with PCP did not seem to significantly change the effect of OLZ, as there was no significant main effect of 'pretreatment' $\left[F_{(1,26)}=0.83, \mathrm{NS}\right]$ and no significant interactions involving 'pretreatment' and other factors (all $P$ values $>0.37$ ).

\section{Experiment 2: Effect of repeated OLZ treatment on CS1 and CS2 avoidance in AMPH-pretreated rats}

Throughout the 11 training sessions, rats from both groups (AMPH-pretreated or VEH-pretreated) showed a similar learning effect, as evidenced by the progressive increase in the number of CS1 and CS2 avoidance responses across sessions (data not shown). Repeated-measures ANOVA indicated that there were significant main effects of 'session' $\left[F_{(10,400)}=19.09, P<0.001\right]$ and 'type' $\left[F_{(1,40)}=96.61, P<0.001\right]$, but no significant main effect of 'pretreatment' $\left[F_{(1,40)}=0.170\right.$, NS] or 'type' $\times$ 'pretreatment' and 'session' $\times$ 'pretreatment' interactions (all $P$ values $>0.40$ ). Once again, the acquisition of CS1 avoidance was faster than the acquisition of CS2 avoidance ['type' $\times$ 'session' interaction, $F_{(10,400)}=10.52$,

Table 1 Summary of the group mean \pm SEM number of CS1 and CS2 avoidances and percent avoidance at the end of the training phase from experiments 1 to 4

\begin{tabular}{|c|c|c|c|c|c|}
\hline \multirow[b]{2}{*}{ Experiment } & \multirow[b]{2}{*}{ Group } & \multicolumn{2}{|c|}{ Mean \pm SEM } & \multicolumn{2}{|c|}{ Avoidance (\%) } \\
\hline & & $\mathrm{CS} 1$ & CS2 & $\mathrm{CS} 1$ & $\mathrm{CS} 2$ \\
\hline \multirow[t]{2}{*}{1} & $\operatorname{PCP}(n=16)$ & $19.38 \pm 0.272$ & $5.25 \pm 0.479$ & 96.9 & 52.5 \\
\hline & VEH $(n=14)$ & $19.29 \pm 0.370$ & $5.21 \pm 0.366$ & 96.4 & 52.1 \\
\hline \multirow[t]{2}{*}{2} & AMPH $(n=12)$ & $18.33 \pm 0.467$ & $4.67 \pm 0.569$ & 91.1 & 46.7 \\
\hline & $\operatorname{VEH}(n=10)$ & $19.10 \pm 0.277$ & $5.60 \pm 0.400$ & 95.5 & 56.0 \\
\hline \multirow[t]{2}{*}{3} & AMPH $(n=16)$ & $19.37 \pm 0.327$ & $5.19 \pm 0.292$ & 96.9 & 51.9 \\
\hline & $\operatorname{VEH}(n=12)$ & $18.50 \pm 0.529$ & $4.50 \pm 0.435$ & 92.5 & 45.0 \\
\hline \multirow[t]{3}{*}{4} & AMPH $(n=13)$ & $18.69 \pm 0.472$ & $4.08 \pm 0.473$ & 93.5 & 40.8 \\
\hline & $\mathrm{PCP}(n=16)$ & $19.13 \pm 0.315$ & $5.56 \pm 0.584$ & 95.6 & 55.6 \\
\hline & VEH $(n=16)$ & $18.81 \pm 0.379$ & $5.25 \pm 0.371$ & $94 . \dagger$ & 52.5 \\
\hline
\end{tabular}

AMPH, amphetamine; $C S$, conditioned stimulus; PCP, phencyclidine; VEH, vehicle. 
Fig. 1

\section{PCP-pretreated rats}

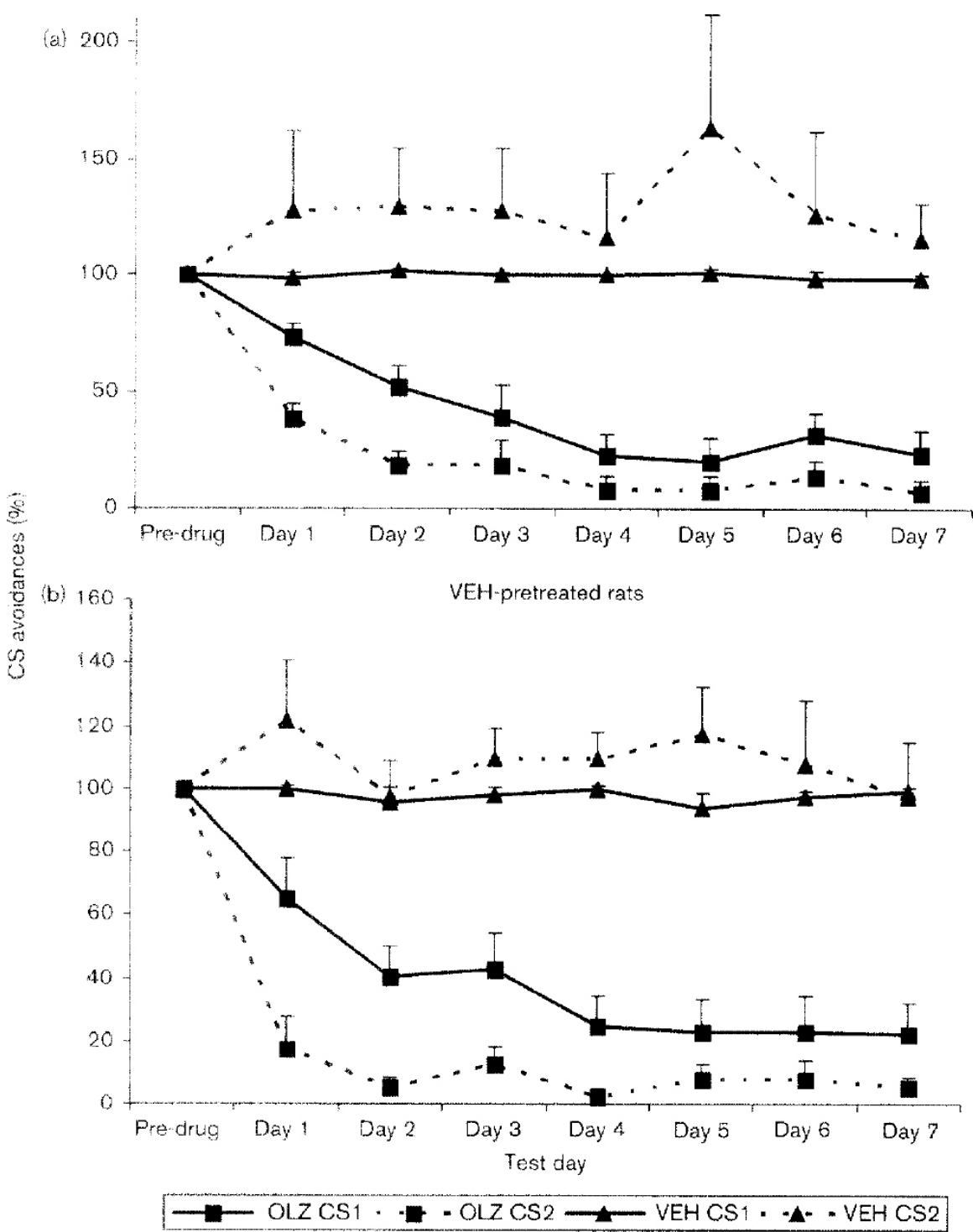

Effects of repeated olanzapine treatment on conditioned stimulus (CS)1 and CS2 avoidance responding in phencyclidine (PCP)-pretreated and vehicle (NEH)-pretreated rats. Each point represents mean avoidance percent $+\mathrm{SEM}$ relative to the last training day. Repeated olanzapine (1.0 mg/kg, subcutaneously, $-60 \mathrm{~min}$ ) treatment significantly distupted CS1 and CS2 avoidance across the 7 daily test sessions in both PCP-pretreated rats (a) and VEH-pretreated rats (b). Olanzapine had a stronger disruptive effect on CS2 avoidance than CS1 avoidance. Throughout the sessions, the disruptive effect was enhanced.

$P<0.001]$. There were no significant group differences in the mean numbers and percentages of CS1 and CS2 avoidances on the last training session of the rats that reached the training criterion (all $P$ values $>0.05$, Table 1 ).

During the OLZ testing phase, the VEH-treated rats maintained their training levels of CS1 and CS2 avoidance throughout the sessions, whereas the OLZ rats showed a progressive decline in both CS1 and CS2 avoidances. Repeated-measures
ANOVA indicated that there were significant main effects of 'session' $\left[F_{(6,108)}=8.129, P<0.001\right]$ and 'drug' $\left[F_{(1,18)}=49.107\right.$, $P<0.001]$, and a significant 'session' $\times$ 'drug' interaction $\left[F_{(6,108)}=3.91, P<0.001\right]$. Unlike the findings from experiment 1 , OLZ did not show a stronger disruptive effect on the CS2 avoidance than the CS1 avoidance (Figure 2), as there was neither a significant main effect of 'type' $\left[F_{(1,18)}=2.29\right.$, NS], nor a significant 'type' $x^{\prime}$ 'drug' interaction $\left[F_{(1,18)}^{(1,18)}=1.42\right.$, NS]. Pretreatment with AMPH did not seem to significantly 


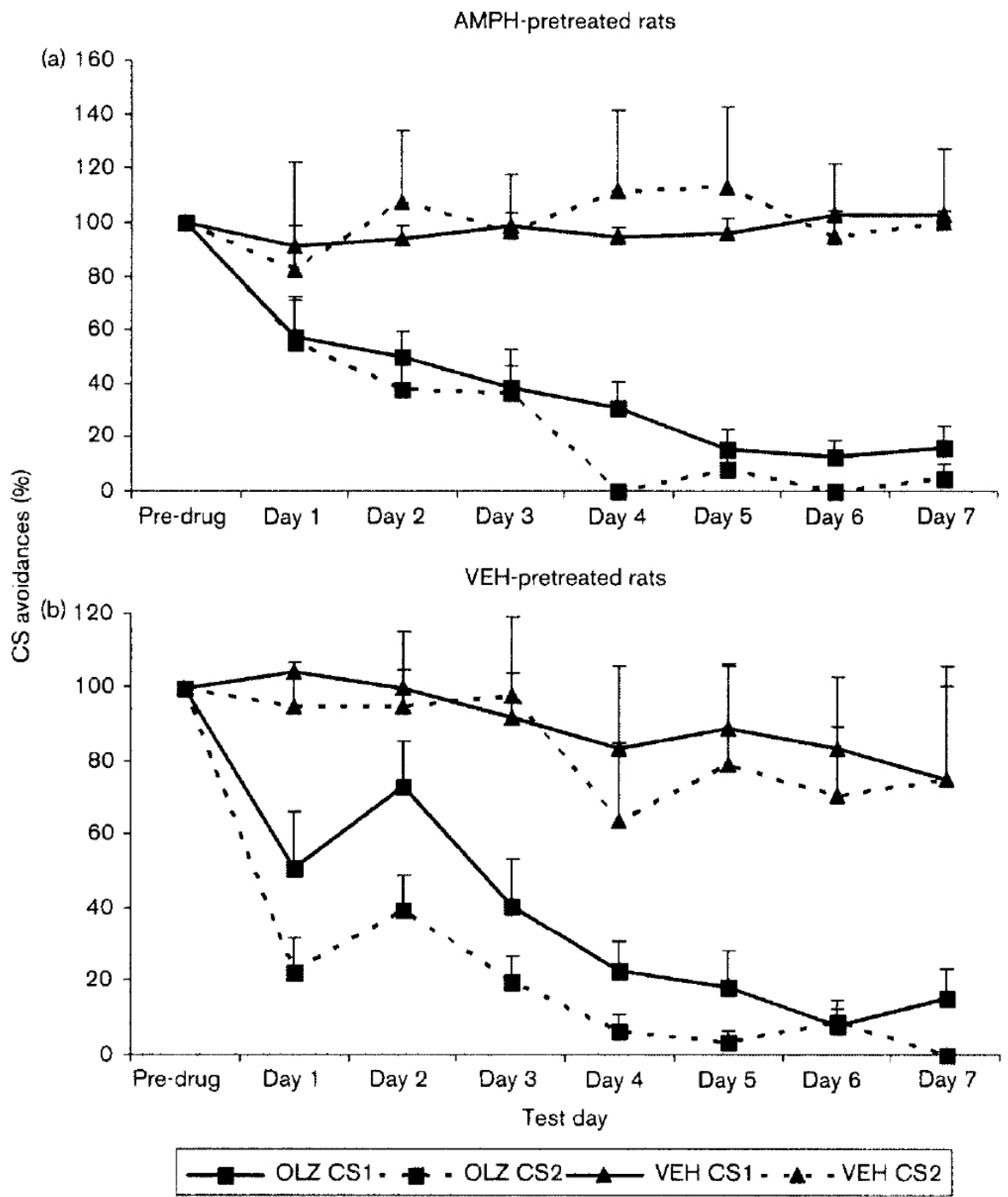

Effects of repeated olanzapine treatment on conditioned stimulus (CS) 1 and CS2 avoidance responding in amphetamine (AMPH)-pretreated and vehicle (VEH)-pretreated rats. Each point represents mean avoidance percent+SEM relative to the last training day. Repeated olanzapine (1.0 mg/kg, subcutaneously, $-60 \mathrm{~min}$ ) treatment significantly disrupted CS1 and CS2 avoidance across the 7 daily test sessions in both AMPH-pretreated rats (a) and VEH-pretreated rats (b). Olanzapine did not show a stronger disruptive effect on CS2 avoidance than CS1 avoidance. Throughout the sessions, the disruptive effect was enhanced.

change the effect of OLZ, as there was no significant main effect of 'pretreatment' $\left[F_{(1,18)}=0.656, \mathrm{NS}\right]$ and no significant interaction involving 'pretreatment' and other factors (all $\mathrm{P}$ values $>0.08)$.

Experiment 3: Replication study of the effect of repeated OLZ treatment on CS1 and CS2 avoidance in AMPH-pretreated rats

Similar to what was seen in experiment 2, rats from both groups (AMPH-pretreated or VEH-pretreated) showed a learning effect throughout the 10 training sessions, as evidenced by the progressive increase in the number of CS1 and CS2 avoidance responses across sessions (data not shown). Repeated-measures ANOVA indicated that there were significant main effects of 'session' $\left[F_{(9,360)}=32.48, P<0.001\right]$ and 'type' $\left[F_{(1,40)}=171.38, P<0.001\right]$, but no significant main effect of 'pretreatment' $[F(1,40)=0.12, \mathrm{NS}]$ or 'type' $\times$ 'pretreatment' and 'session' $x$ 'pretreatment' interactions (all $P$ values $>0.83$ ). Once again, the acquisition of CS1 avoidance was faster than the acquisition of CS2 avoidance ['type' $\times$ 'session' interaction, $\left.F_{(9,360)}=15.03, P<0.001\right]$. There were no signifi- 
Fig. 3

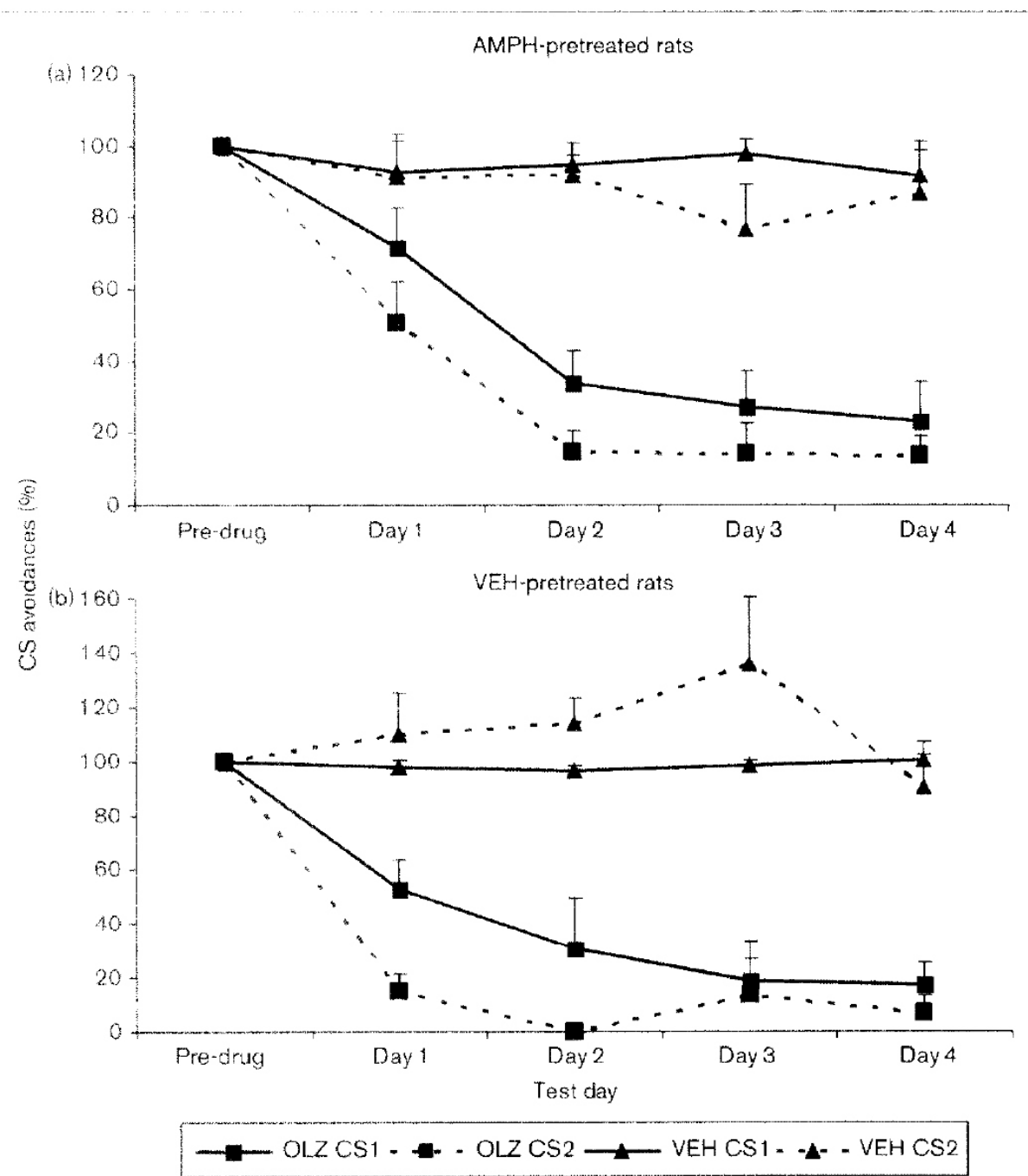

Replication of effects of repeated olanzapine treatment on conditioned stimulus (CS) 1 and CS2 avoidance responding in amphetamine (AMPH)pretreated and vehicle (VEH)-pretreated rats. Each point represents mean avoidance percent+SEM relative to the last training day. Repeated olanzapine $(1.0 \mathrm{mg} / \mathrm{kg}$, subcutaneously, $-60 \mathrm{~min})$ treatment significantly disrupted CS1 and CS2 avoidance across the 7 daily test sessions in both AMPH-pretreated rats (a) and VEH-pretreated rats (b). Olanzapine had a stronger disruptive effect on CS2 avoidance than CS1 avoidance. Throughout the sessions, the disruptive effect was enhanced.

cant group differences in the mean numbers and percentages of CS1 and CS2 avoidances on the last training session for rats that reached the training criterion (all $P$ values $>0.05$, Table 1).

During the OLZ testing phase, the VEH-treated rats maintained their training levels of CS1 and CS2 avoidance throughout the sessions, whereas the OLZ rats showed a progressive decline in both CS1 and CS2 avoidances. Repeated-measures ANOVA indicates that there were significant main effects of 'session' $\left[F_{(3,72)}=5.63, P<0.002\right]$ and 'drug' $\left[F_{(1,24)}=121.53, P<\right.$ 0.001], and a significant effect of 'session' $\times$ 'drug' interaction $\left[F_{(3,72)}=5.09, P<0.005\right]$. In addition, OLZ had a stronger disruptive effect on the CS2 avoidance than CS1 avoidance as it caused a sharper decline in the CS2 avoidance than the CS1 avoidance relative to the baseline (Figure 3). Statistical analysis confirmed this observation ['type' $x$ 'drug' interaction: $\left.F_{(1,24)}=6.85, P<0.02\right]$. Similar to experiment 2 , pretreatment of AMPH did not significantly change the effect of OLZ, as there was no significant main effect of 'pretreatment' $\left[F_{(1,24)}=\right.$ $0.058, N S]$ and no significant interaction involving 'pretreatment' and other factors (all $P$ values $>0.11$ ).

\section{Experiment 4: Effect of repeated RIS and OLZ treatment on CS1 and CS2 avoidance in PCP-pretreated and AMPH-pre- treated rats}

After 3 weeks of withdrawal from PCP and AMPH treatment, all rats were tested for locomotor activity after an acute injection of PCP $(1.5 \mathrm{mg} / \mathrm{kg}$, s.c.) or AMPH (0.5 mg/kg, s.c.) 
Fig. 4
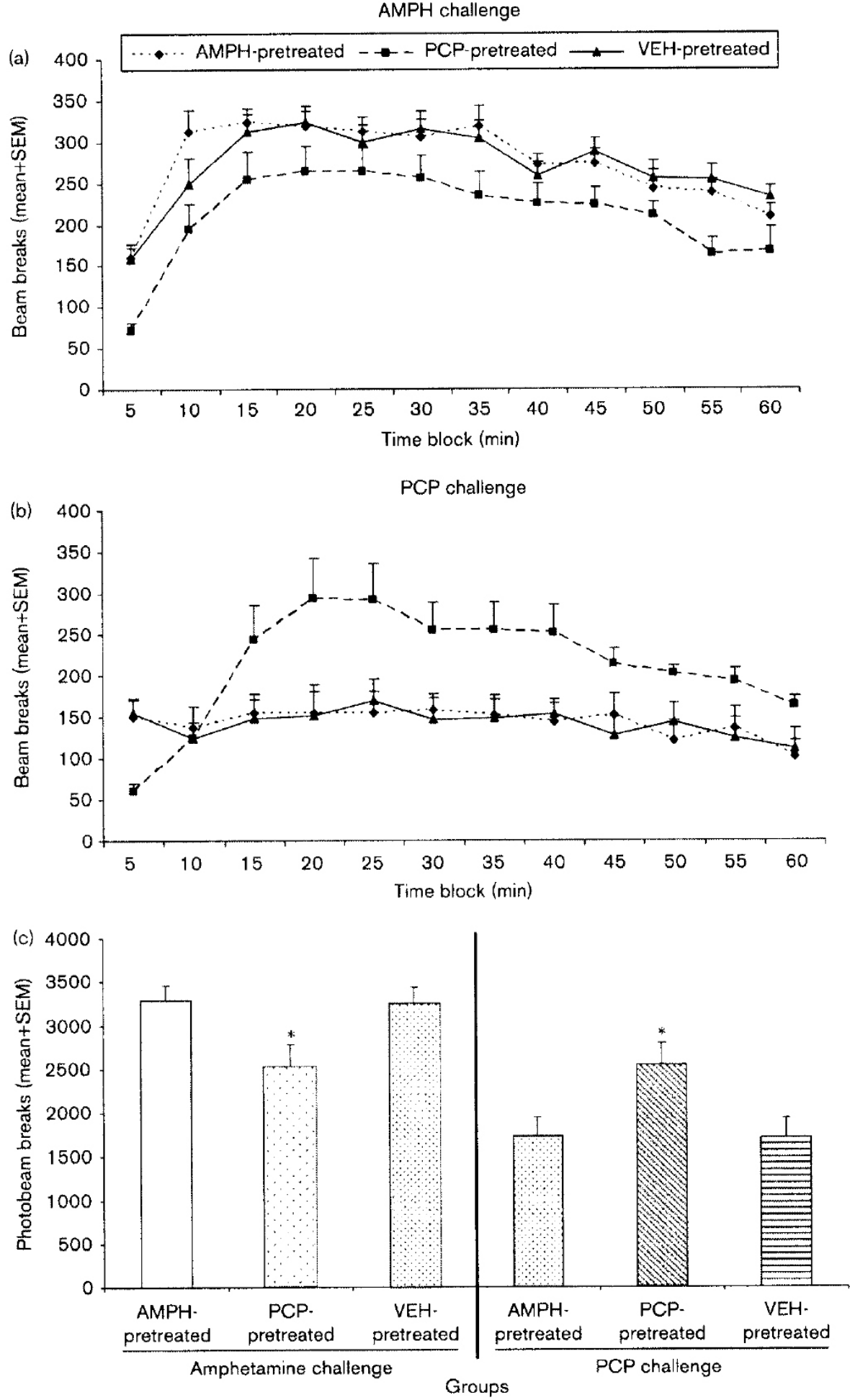

Effects of amphetamine (AMPH) and phencyclidine (PCP) pretreatment on locomotor activity. Rats were pretreated with $A M P H[1.0-3.0 \mathrm{mg} / \mathrm{kg}$, subcutaneously (s.c.)] or PCP (3.0 mg/kg, s.c.) for 3 weeks. After a 3-week period of withdrawal, they were challenged with $A M P H(0.5 \mathrm{mg} / \mathrm{kg}, \mathrm{s.c}$.) or PCP $(1.5 \mathrm{mg} / \mathrm{kg}$, s.c.). Data are shown as activity counts in $125-\mathrm{min}$ blocks (e.g. $-60 \mathrm{~min})$ after the drug challenges $(\mathrm{a}, \mathrm{b})$ or total activity counts (c). ${ }^{*} P<0.05$ significant difference between the PCP-pretreated groups and the AMPH-pretreated or VEH-pretreated groups. 
for 60 min (12 5-min blocks) to assess the behavioral sensitization effect (Figure 4a and b). Repeated-measures ANOVA with the 'pretreatment' condition (PCP, AMPH, or VEH) and the 'challenge drugs' (PCP or AMPH) as the betweensubjects factors and the 5-min time block ('block') as the within-subjects factor indicated that there was a significant

Fig. 5

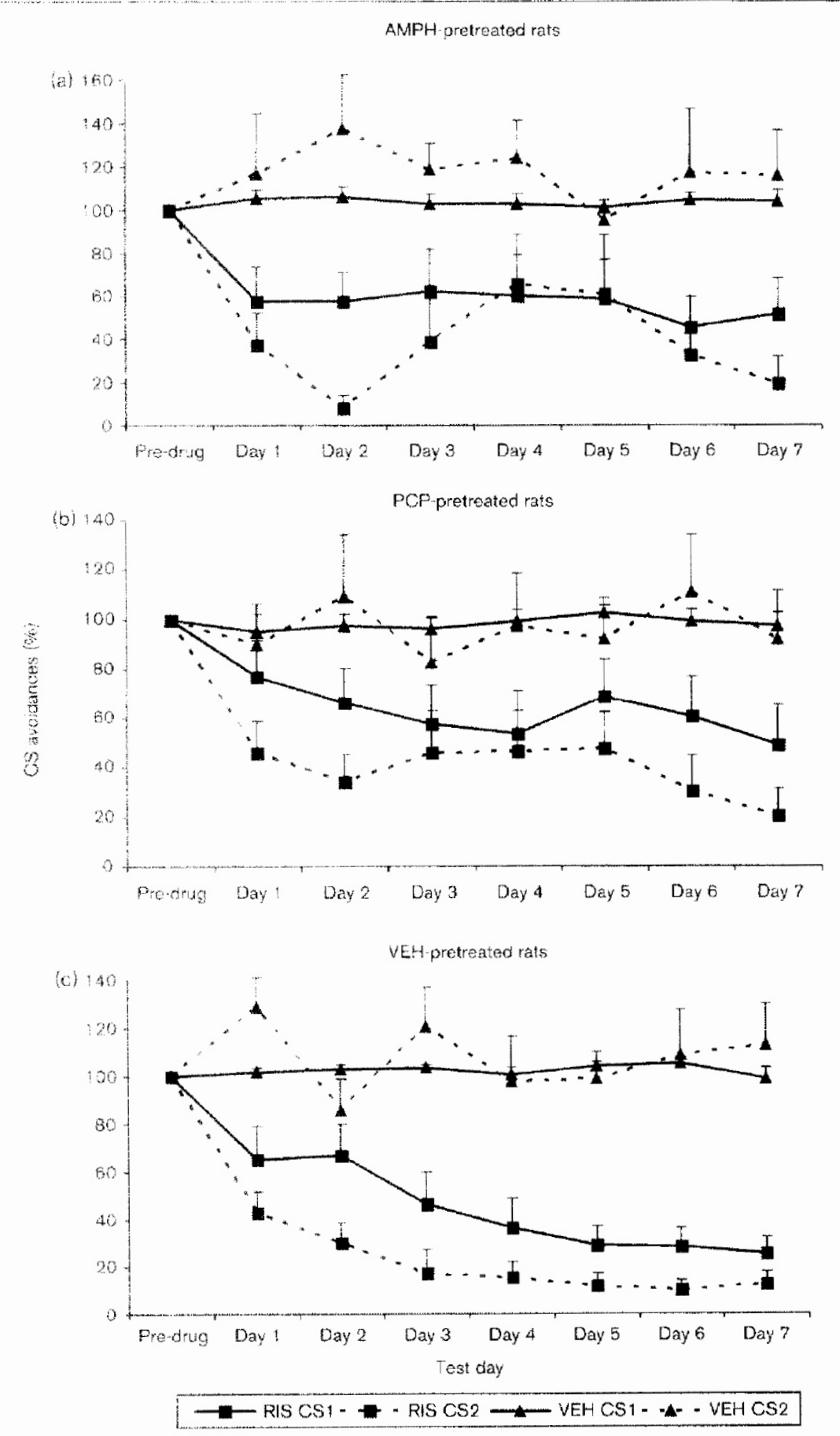

Effects of repeated risperidone (RIS) treatment on conditioned stimulus (CS)1 and CS2 avoidance responding in amphetamine (AMPH)-pretreated, phencyclidine (PCP)-pretreated, or vehicle $(V E H)$-pretreated rats. Each point represents mean avoidance percent $+S E M$ relative to the second to last training day. Repeated RIS $(0.33 \mathrm{mg} / \mathrm{kg}$, subcutaneously, $-60 \mathrm{~min})$ treatment significantly disrupted CS 1 and CS2 avoidance across the 7 daily test sessions in AMPH-pretreated (a), PCP-pretreated (b), and VEH-pretreated rats (c). RIS had a stronger disruptive effect on CS2 avoidance than CS1 avoidance. Throughout the sessions, the disruptive effect was enhanced 
Fig. 6

AMPH-pretreated rats
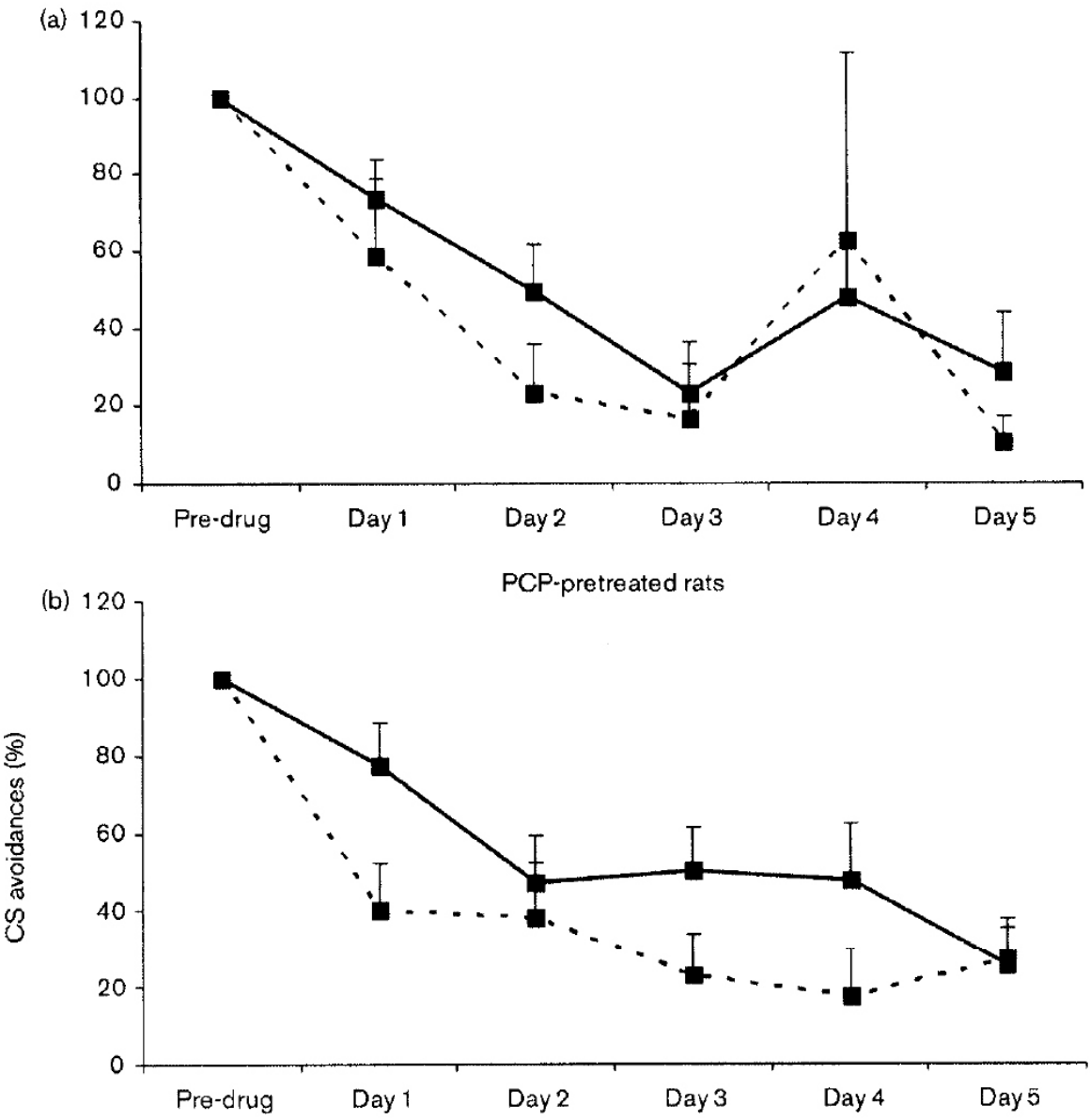

VEH pretreated rats

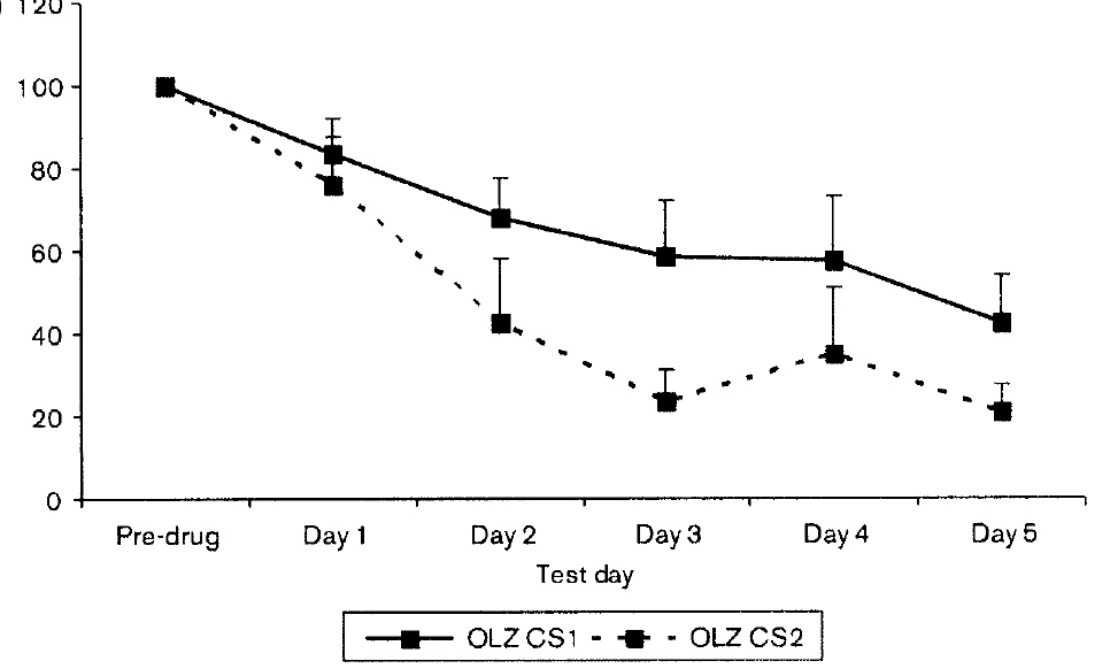

Effects of repeated olanzapine treatment on conditioned stimulus (CS)1 and CS2 avoidance responding in amphetamine (AMPH)-pretreated, phencyclidine (PCP)-pretreated, or vehicle (VEH)-pretreated rats. Each point represents mean avoidance percent + SEM relative to the second to last training day. Repeated olanzapine $(1.0 \mathrm{mg} / \mathrm{kg}$, subcutaneously, $-60 \mathrm{~min})$ treatment significantly disrupted CS1 and CS2 avoidance across the 5 daily test sessions in AMPH-pretreated (a), PCP-pretreated (b), and VEH-pretreated rats (c). Olanzapine had a stronger disruptive effect on CS2 avoidance than CS1 avoidance. Throughout the sessions, the disruptive effect was enhanced. 
main effect of 'challenge drugs' $\left[F_{(1,54)}=33.62, P<0.001\right]$ and a significant 'challenge drugs' $\times$ 'pretreatment' interaction $\left[F_{(2,54)}=8.64, P<0.001\right]$. Overall, AMPH caused a significantly higher increase in the number of photobeam breaks than did PCP. This effect was more pronounced in the AMPH-pretreated and VEH-pretreated rats than in the PCP-pretreated ones. Over the 60-min testing period, there was a significant main effect of 'block' $\left[F_{(11,594)}=33.39, P<0.001\right]$ and significant interactions between 'block' and 'pretreatment' $\left[F_{(22,594)}\right.$ $=4.12, P<0.001]$, 'block' and 'challenge drugs' $\left[F_{(11,594)}=\right.$ 5.16, $P<0.001]$, and 'block', 'pretreatment', And 'challenge drugs' $\left[F_{(22,594)}=33.62, P<0.002\right]$. Inspection of Figure $4 \mathrm{~b}$ suggests that $\mathrm{PCP}$ pretreatment significantly potentiated the effect of challenge treatment of PCP, as the PCP-pretreated rats showed a significantly higher increase in the number of photobeam breaks than the AMPH-pretreated or VEH-pretreated rats. However, the AMPH pretreatment effect was less obvious, as $0.5 \mathrm{mg} / \mathrm{kg}$ dose of AMPH caused a similar level of increase in motor activity in AMPH-pretreated and VEH-pretreated groups, an effect independent of pretreatment conditions; thus, the potential AMPH sensitization effect might be masked. For the total activity counts (Figure 4c), two-group comparisons indicate that under the AMPH challenge, the PCP-pretreated group showed a significantly lower increase in motor activity than the other two groups (all $P$ values < 0.029); whereas under the PCP challenge, the PCP-pretreated group showed a significantly higher increase in motor activity than the other groups (all $P$ values $<0.05)$.

Fifty-two rats finished all 10 training sessions. They showed a similar level of learning, as evidenced by the progressive increase in the number of CS1 and CS2 avoidance responses across sessions (data not shown). Repeated-measures ANOVA indicated that there were significant main effects of 'session' $\left[F_{(9,279)}=34.80, P<0.001\right]$ and 'type' $\left[F_{(1,31)}\right.$ $=3036.12, P<0.001]$ but no significant main effect of 'pretreatment' $\left[F_{(2,31)}=0.97, \mathrm{NS}\right]$ or 'type' $\times$ 'pretreatment' and 'session' $\times$ 'pretreatment' interactions (all $P$ values $>0.085$ ). The acquisition of CS1 avoidance was faster than the acquisition of CS2 avoidance ['type' $\times$ 'session' interaction, $F_{(1,31)}$ $=3036.12, P<0.001]$, a result that was expected from the experimental design in which only half of the CS2 trials were followed by shock, whereas all the CS1 trials were followed by shock if the rats failed to respond. There were no significant group differences in the mean numbers and percentages of CS1 and CS2 avoidances on the last training session for rats that reached the training criterion (all $P$ values $>0.05$, Table 1 ).

During the RIS testing phase, the VEH-treated rats maintained their training levels of CS1 and CS2 avoidance throughout the sessions, whereas the RIS-treated rats showed a progressive decline in both CS1 and CS2 avoid- ances regardless of pretreatment (Figure 5a-c). Repeatedmeasures ANOVA indicated that there were significant main effects of 'session' $\left[F_{(6,234)}=2.19, P<0.05\right]$, 'drug' $\left[F_{(1,39)}\right.$ $=48.44, P<0.001]$, and a significant three-way 'session' $\times$ 'drug' $\times$ 'pretreatment' interaction $\left[F_{(12,234)}=1.81, P<0.05\right]$. In addition, RIS had a stronger disruptive effect on the CS2 avoidance than CS1 avoidance. There was a significant 'type' $\times$ 'drug' interaction $\left[F_{(1,39)}=6.38, P<0.02\right]$. Pretreatment with PCP and AMPH did not seem to alter the effect of RIS, as there was no significant main effect of 'pretreatment' $\left[F_{(2,39)}=\right.$ $0.97, \mathrm{NS}]$ and no significant 'pretreatment' and 'drug' interaction $\left[F_{(2,39)}=2.04, \mathrm{NS}\right]$.

During the OLZ testing phase, rats previously tested under VEH were switched to OLZ and further tested for five sessions (Figure 6). Similar to results from the first three experiments, the OLZ rats showed a progressive decline in both CS1 and CS2 avoidances across sessions in comparison with their avoidance performance on the last VEH session. Repeated-measures ANOVA indicated that there was a significant main effect of 'session' $\left[F_{(4,80)}=5.05, P<0.001\right]$. In addition, OLZ had a stronger disruptive effect on the CS2 avoidance than CS1 avoidance as there was a significant main effect of 'type' $\left[F_{(1,20)}=17.46, P<0.001\right]$. Pretreatment with PCP or AMPH did not significantly change the effect of OLZ, as there was no significant main effect of 'pretreatment' $\left[F_{(2,20)}=0.94, \mathrm{NS}\right]$ and no significant interactions involving 'pretreatment' and other factors (all $P$ values $>$ $0.14)$.

\section{Discussion}

This study examined the behavioral mechanism of the atypical antipsychotics OLZ and RIS in the CAR model in PCP-pretreated and AMPH-pretreated rats, two widely used putative animal models of schizophrenia. We used a modified avoidance response task in which two different salient CS signals were used to elicit avoidance response, and found that both OLZ and RIS produced a progressive decrease in avoidance responding across sessions in drug naive, as well as PCP-pretreated and AMPH-pretreated rats, confirming and extending our previous findings ( $\mathrm{Li}$ et al., 2007). More importantly, we found that OLZ and RIS preferentially disrupted a less salient CS (CS2)-elicited avoidance to a highly salient CS (CS1)-elicited avoidance, a finding that is consistent with the view that antipsychotics disrupt avoidance responding primarily by selectively attenuating the motivational salience of the CS (Li et al., 2007). Furthermore, we did not find any consistent effect of PCP and AMPH pretreatment on the decrease in avoidance responding elicited by OLZ and RIS, suggesting that behavioral action of antipsychotics operates similarly in different populations of subjects. 
Our previous study provides several pieces of evidence suggesting that HAL at noncataleptic and clinically relevant doses $(<0.05 \mathrm{mg} / \mathrm{kg}$, s.c, based on the striatal dopamine D2 occupancy data; (Kapur et al., 2003) disrupt avoidance responding primarily by attenuating the motivational salience of the CS (Li et al., 2004, 2007). In other words, HAL is suggested to decrease the ability of the CS to elicit active motor response to terminate the CS and avoid the US (Beninger, 1989; Berridge and Robinson, 1998). In this study, we used a novel CAR task and asked whether or not atypical OLZ and RIS also disrupt avoidance responding by this mechanism. In this task, we created two types of CS signals (CS1 and CS2) that varied in their motivational salience (e.g. ability to elicit avoidance). This was achieved by pairing the CS1 with the US in every CS1 trial, whereas pairing the CS2 with the US in only half of the CS2 trials if the rats failed to respond. In addition, we used more CS1 trials (20) than CS2 trials (10) in each training/testing session. That the CS2 was rendered to be a less salient signal was reflected by the following two findings: first, at the end of training, the mean numbers and percentages of CS2elicited avoidances (4.085.60 out of 10 , or $40.8-56.0 \%$ ) were much lower than CS1elicited ones (18.23-19.38 out of 20, or 91.1-96.9\%) (Table 1); and second, rats acquired CS2 avoidance at a much slower rate than CS1 avoidance. As the sensory and motor functions required to perform CS1 and CS2 avoidances are the same, the preferentially disruptive effect of OLZ and RIS on CS2 avoidance over CS1 avoidance cannot be attributed to their actions on sensory and motor functions, but rather indicates an action on incentive motivation of rats. In the CAR model, the 'incentive motivation' refers to the motivation instigated by a salient stimulus that drives organisms to actively pursue a safe environment or situation. Thus, HAL, OLZ, and RIS may disrupt avoidance responding by decreasing incentive motivation of rats to respond to the CS1 and CS2. This conceptualization of 'incentive motivation' is very similar to that of Salamone and Correa (2002), who suggest that low doses of dopamine antagonists, such as HAL, impair activational aspects of motivation, making animals less likely to engage in instrumental responses to obtain positive rewards. Alternatively, it is also possible that the differential drug effects on CS1 and CS2 avoidance may result from the different baseline levels of avoidance. On the last training day, the mean CS1 avoidance from all four experiments was about $95 \%$, whereas the mean CS2 avoidance was only $50 \%$. This difference in avoidance responding rate at baseline may influence the magnitude of the disruptive effects of APDs, independent of motivational salience of CS1 and CS2. In the literature, there are many illustrations of this phenomenon that differences in scheduling of events and patterns of behavioral responding can determine the direction and magnitude of the behavioral effects of drugs (Dews, 1976; Spealman et al., 1983; Barrett, 2002; McMillan and Katz, 2002; Barrett et al., 2008). For example, it has been shown that under certain conditions, clozapine and chlordiazepoxide can decrease or increase a lever-pressing response (presentation of food, presentation of electric shock or termination of a stimulus associated with electric shock) under different schedules of reinforcement (a fixedinterval schedule or a multiple schedule with alternating fixed-ratio and fixed-interval components) (Spealman et al., 1983). To distinguish between these two alternative interpretations ("motivational salience" versus "different baseline response"), it is ideal to create a condition in which CS1 and CS2 avoidance have equivalent baselines but different motivational saliencies or have equivalent motivational saliencies but different baselines. One way to achieve this is to make the number of CS2-shock pairings equal to the number of CS1-shock pairings but to maintain the percentage of CS2 and CS1 trials followed by shock at 50\% and $100 \%$ respectively (i.e., the total number of CS2 trials are twice the number of CS1 trials). Under this condition, the baselines of CS1 and CS2 avoidance will be similar, but CS1 will still be more salient than CS2 due to the fact that it will be paired with shock to a greater proportion of its presentations than CS2. If the motivational salience interpretation is correct, we expect that antipsychotics would still decrease CS2 avoidance to a greater extent than CS1 avoidance. On the other hand, if the different baseline interpretation is correct, we expect that antipsychotics would decrease CS1 and CS2 avoidance to a similar extent. Future work is needed to determine the relative validity of each interpretation.

In this study, we also examined whether antipsychotics disrupt avoidance responding in putative animal models of schizophrenia in the same way as in normal animals. This was done by using two widely used pharmacological models of schizophrenia, AMPH sensitization, and PCP sensitization (Robinson and Becker, 1986; Xu and Domino, 1994; Phillips et al., 2001; Castner et al., 2005; Featherstone et al., 2007). It is well known that repeated intermittent exposure to psychostimulants such as AMPH and dissociative anesthetics such as PCP can induce psychotic-like disorders very similar to psychosis observed in patients with schizophrenia (Bell, 1965; Janowsky and Risch, 1979; Javitt and Zukin, 1991). Both classes of psychotomimetic drugs also exacerbate existing psychotic symptoms in acute patients with schizophrenia (Itil et al., 1967; Snyder, 1973; Murray, 2002). Animals repeatedly treated with AMPH or PCP show an array of longlasting molecular, cellular, and behavioral changes similar to those observed in patients with schizophrenia (Robinson and Becker, 1986; Nestler, 2001; Martinez et al., 2005), such as behavioral sensitization (Segal and Mandell, 1974; Segal et al., 1981) and various psychological dysfunctions such as deficits in attention (Geyer et al., 2001; Tenn et al., 2005), working memory (Bruto et al., 1984; Jentsch et al., 1997; Jentsch and Anzivino, 2004; Marrs et al., 2005), behavioral flexibility and executive functioning (Jentsch and Taylor, 2001; Fletcher et al., 2005), and social interaction (Sams-Dodd, 1998a; Ellenbroek and Cools, 2000). In this study, we used the AMPH and PCP treatment regimens that are commonly used in the literature (Jentsch et al., 1997; Jentsch and Taylor, 2001; Murphy et al., 2001; Pezze et al., 2002; Russig et al., 2002; Rodefer et al., 2005; Dunn and Killcross, 2006; Peleg-Raibstein et al., 2006; Peleg-Raibstein and Feldon, 2008), and found that OLZ and RIS had a similar effect in PCP-pretreated and AMPH- 
pretreated rats compared with saline rats. This finding suggests that the behavioral mechanism of antipsychotic action might operate in the same manner in different populations of subjects.

One caveat concerning this conclusion is that we only found the long-term sensitization effect with PCP, but not with $\mathrm{AMPH}$ (Figure 4). This lack of strong demonstration of AMPH sensitization effects was surprising given the fact that a similar 3-week sensitization regimen has been shown in other studies to be effective in inducing a longlasting locomotor sensitization and deficits in latent inhibition and prepulse inhibition (Tenn et al., 2003, 2005) and that we did find a robust PCP sensitization effect. The apparatuses used in those studies were also identical to ours. Although the exact cause of this difference is unknown, it is reasonable to assume that this pretreatment schedule may not reliably produce sensitization to AMPH. Thus, whether antipsychotics work through a similar behavioral mechanism in AMPH-based animal models of schizophrenia is still an open question. Further studies may be needed to clarify this point.

This study may provide a clue on the behavioral mechanism of antipsychotic action in the treatment of schizophrenia. Kapur (2003) theorized that APDs work psychologically by suppressing incentive learning or weakening motivational salience so that new aberrant beliefs are less likely to form and previously formed aberrant memories are more likely to be extinguished. It is thought that APDs, by inhibiting the dopamine system, may attenuate the (aberrant) reinforcing effectiveness of stimuli that the patient is experiencing. This may lead to the almost immediate halt of the generation of new psychotic material and allows for the gradually progressive extinction of psychotic symptoms. This theory of action of antipsychotics is not dissimilar to the findings from this study showing that antipsychotics disrupt avoidance responding (a behavioral proxy of 'psychosis') by attenuating the motivational salience of the CS.

Taken together, this study used a novel avoidance conditioning model and showed that atypical antipsychotics OLZ and RIS disrupt avoidance responding elicited by a weak stimulus to a greater extent and at a faster rate than one elicited by a strong stimulus. This effect is seen in normal rats as well as in rats that were pretreated with AMPH or PCP. These findings suggest that antipsychotics may achieve their therapeutic effect by attenuating the motivational salience of stimuli.

\section{Acknowledgements}

This study was funded in part by a support from the Nebraska Tobacco Settlement Biomedical Research Development Funds, and NARSAD Young Investigator Award (20072009) to M.L. The authors thank the two anonymous reviewers for their insightful comments and the suggestion of the alternative explanation (i.e. differing baselines) of the disruptive effects of antipsychotics on CS1 and CS2 avoidance.

\section{References}

Ader R, Clink DW (1957). Effects of chlorpromazine on the acquisition and extinction of an avoidance response in the rat. J Pharmacol Exp Ther 131: 144-148.

Arnt J (1982). Pharmacological specificity of conditioned avoidance response inhibition in rats: inhibition by neuroleptics and correlation to dopamine receptor blockade. Acta Pharmacol Toxicol (Copenh) 51: 321-329.

Barrett JE (2002). The emergence of behavioral pharmacology. Mol Intervent 2: 470-475.

Barrett JE, Bergman J Peter B (2008). Dews and pharmacological studies on behavior. J Pharmacol Exp Ther 326: 683-690.

Bell DS (1965). Comparison of amphetamine psychosis and schizophrenia. Br J Psychiatry 111: 701-707.

Beninger RJ (1989). The role of serotonin and dopamine in learning to avoid aversive stimuli. In: Archer T, Nilsson L, editors. Aversion, Avoidance, and Anxiety: Perspective on Aversively Motivated Behavior. Hillsdale, New Jersey: Lawrence Erlbaum Associates. pp. 265-284.

Berridge KC, Robinson TE (1998). What is the role of dopamine in reward: hedonic impact, reward learning, or incentive salience? Brain Res Brain Res Rev 28: 309-369.

Bignami G (1978). Effects of neuroleptics, ethanol, hypnotic-sedatives, tranquilizers, narcotics, and minor stimulants in aversive paradigms. In: Anisman H, Bignami G, editors. Psychopharmacology of Aversively Motivated Behavior. New York and London: Plenum Press. pp. 385-453.

Bruto V, Beauchamp C, Zacharko RM, Anisman H (1984). Amphetamine-induced perseverative behavior in a radial arm maze following DSP4 or 6-OHDA pretreatment. Psychopharmacology (Berl) 83: 62-69.

Castner SA, Vosler PS, Goldman-Rakic PS (2005). Amphetamine sensitization impairs cognition and reduces dopamine turnover in primate prefrontal cortex. Biol Psychiatry 57: 743-751.

Cook L, Davidson AB (1978.) Behavioral pharmacology: animal models invovling aversive control of behavior. In: Lipton MA, DiMascio A, Killam K, editors. Psychopharmacology: A Generation of Progress. New York: Raven. pp. 563-567.

Dews PB (1976). Interactions of behavioral effects of drugs. Ann N Y Acad Sci 281: 50-63.

Dunn MJ, Killcross S (2006). Clozapine but not haloperidol treatment reverses sub-chronic phencyclidine-induced disruption of conditional discrimination performance. Behav Brain Res 175: 271-277.

Ellenbroek BA, Cools AR (2000). Animal models for the negative symptoms of schizophrenia. Behav Pharmacol 11: 223-233.

Featherstone RE, Kapur S, Fletcher PJ (2007). The amphetamineinduced sensitized state as a model of schizophrenia. Prog Neuropsychopharmacol Biol Psychiatry 31: 1,556-1,571.

Fletcher PJ, Tenn CC, Rizos Z, Lovic V, Kapur S (2005). Sensitization to amphetamine, but not PCP, impairs attentional set shifting: reversal by a $\mathrm{D}_{1}$ receptor agonist injected into the medial prefrontal cortex. Psychopharmacology (Berl) 183: 190-200.

Geyer MA, Krebs-Thomson K, Braff DL, Swerdlow NR (2001). Pharmacological studies of prepulse inhibition models of sensorimotor gating deficits in schizophrenia: a decade in review. Psychopharmacology (Berl) 156: 117-154.

Itil T, Keskiner A, Kiremitci N, Holden JM (1967). Effect of phencyclidine in chronic schizophrenics. Can Psychiatr Assoc J 12: 209-212.

Janowsky DS, Risch C (1979). Amphetamine psychosis and psychotic symptoms. Psychopharmacology (Berl) 65: 73-77.

Janssen PAJ, Niemegeers CJE, Schellekens KHL (1965). Is it possible to predict the clinical effects of neuroleptic drugs (major tranquilizers) from animal data? Arzneimittelforschung 15: 104-117.

Javitt DC, Zukin SR (1991). Recent advances in the phencyclidine model of schizophrenia. Am J Psychiatry 148: 1,301-1,308. 
Jentsch JD, Anzivino LA (2004). A low dose of the alpha ${ }_{2}$ agonist clonidine ameliorates the visual attention and spatial working memory deficits produced by phencyclidine administration to rats. Psychopharmacology (Berl) 175: 76-83.

Jentsch JD, Roth RH (1999). The neuropsychopharmacology of phencyclidine: from NMDA receptor hypofunction to the dopamine hypothesis of schizophrenia. Neuropsychopharmacology 20: 201-225.

Jentsch JD, Taylor JR (2001). Impaired inhibition of conditioned responses produced by subchronic administration of phencyclidine to rats. Neuropsychopharmacology 24: 66-74.

Jentsch JD, Tran A, Le D, Youngren KD, Roth RH (1997). Subchronic phencyclidine administration reduces mesoprefrontal dopamine utilization and impairs prefrontal cortical-dependent cognition in the rat. Neuropsychopharmacology 17: 92-99.

Kapur S (2003). Psychosis as a state of aberrant salience: a framework linking biology, phenomenology, and pharmacology in schizophrenia. Am J Psychiatry 160: 13-23.

Kapur S, Remington G (2001). Atypical antipsychotics: new directions and new challenges in the treatment of schizophrenia. Annu Rev Med 52: 503-517.

Kapur S, VanderSpek SC, Brownlee BA, Nobrega JN (2003). Antipsychotic dosing in preclinical models is often unrepresentative of the clinical condition: a suggested solution based on in vivo occupancy. J Pharmacol Exp Ther 305: 625-631.

Kuribara H, Tadokoro S (1981). Correlation between antiavoidance activities of antipsychotic drugs in rats and daily clinical doses. Pharmacol Biochem Behav 14: 181-192.

Li M, Parkes J, Fletcher PJ, Kapur S (2004). Evaluation of the motor initiation hypothesis of APD-induced conditioned avoidance decreases. Pharmacol Biochem Behav 78: 811-819.

Li M, Fletcher PJ, Kapur S (2007). Time course of the antipsychotic effect and the underlying behavioral mechanisms. Neuropsychopharmacology 32: 263-272.

Marrs W, Kuperman J, Avedian T, Roth RH, Jentsch JD (2005). Alpha-2 adrenoceptor activation inhibits phencyclidine-induced deficits of spatial working memory in rats. Neuropsychopharmacology 30: 1,500-1,510.

Martinez V, Parikh V, Sarter M (2005). Sensitized attentional performance and Fos-immunoreactive cholinergic neurons in the basal forebrain of amphetamine-pretreated rats. Biol Psychiatry 57: 1,138-1,146.

McMillan DE, Katz JL (2002). Continuing implications of the early evidence against the drive-reduction hypothesis of the behavioral effects of drugs. Psychopharmacology (Berl) 163: 251-264.

Murphy CA, Fend M, Russig H, Feldon J (2001). Latent inhibition, but not prepulse inhibition, is reduced during withdrawal from an escalating dosage schedule of amphetamine. Behav Neurosci 115: 1,247-1,256.

Murray JB (2002). Phencyclidine (PCP): a dangerous drug, but useful in schizophrenia research. J Psychol 136: 319-327.

Nestler EJ (2001). Molecular neurobiology of addiction. Am J Addict 10: 201-217.

Peleg-Raibstein D, Feldon J (2008). Effects of withdrawal from an escalating dose of amphetamine on conditioned fear and dopamine response in the medial prefrontal cortex. Behav Brain Res 186: $12-22$.

Peleg-Raibstein D, Sydekum E, Feldon J (2006). Differential effects on prepulse inhibition of withdrawal from two different repeated administration schedules of amphetamine. Int J Neuropsychopharmacol 9: 737-749.

Pezze MA, Feldon J, Murphy CA (2002). Increased conditioned fear response and altered balance of dopamine in the shell and core of the nucleus accumbens during amphetamine withdrawal. Neuropharmacology 42: 633-643.

Phillips M, Wang C, Johnson KM (2001). Pharmacological characterization of locomotor sensitization induced by chronic phencyclidine administration. J Pharmacol Exp Ther 296: 905-913.

Robinson TE, Becker JB (1986). Enduring changes in brain and behavior produced by chronic amphetamine administration: a review and evaluation of animal models of amphetamine psychosis. Brain Res 396: 157-198.

Rodefer JS, Murphy ER, Baxter MG (2005). PDE10A inhibition reverses subchronic PCP-induced deficits in attentional setshifting in rats. Eur J Neurosci 21: 1,070-1,076.

Russig H, Murphy CA, Feldon J (2002). Clozapine and haloperidol reinstate latent inhibition following its disruption during amphetamine withdrawal. Neuropsychopharmacology 26: 765-777.

Russig H, Murphy CA, Feldon J (2003). Prepulse inhibition during withdrawal from an escalating dosage schedule of amphetamine. Psychopharmacology (Berl) 169: 340-353.

Sams-Dodd F (1998a). Effects of continuous D-amphetamine and phencyclidine administration on social behaviour, stereotyped behaviour, and locomotor activity in rats. Neuropsychopharmacology 19: 18-25.

Sams-Dodd F (1998b). A test of the predictive validity of animal models of schizophrenia based on phencyclidine and D-amphetamine. Neuropsychopharmacology 18: 293-304.

Salamone JD, Correa M (2002). Motivational views of reinforcement: implications for understanding the behavioral functions of nucleus accumbens dopamine. Behav Brain Res 137: 3-25.

Segal DS, Mandell AJ (1974). Long-term administration of d-amphetamine: progressive augmentation of motor activity and stereotypy. Pharmacol Biochem Behav 2: 249-255.

Segal DS, Geyer MA, Schuckit MA (1981). Stimulant-induced psychosis: an evaluation of animal methods. Essays Neurochem Neuropharmacol 5: 95-129.

Shannon HE, Hart JC, Bymaster FP, Calligaro DO, DeLapp NW, Mitch CH, et al. (1999). Muscarinic receptor agonists, like dopamine receptor antagonist antipsychotics, inhibit conditioned avoidance response in rats. J Pharmacol Exp Ther 290: 901-907.

Snyder SH (1973). Amphetamine psychosis: a 'model' schizophrenia mediated by catecholamines. Am J Psychiatry 130: 61-67.

Spealman RD, Kelleher RT, Goldberg SR, DeWeese J, Goldberg DM (1983). Behavioral effects of clozapine: comparison with thioridazine, chlorpromazine, haloperidol and chlordiazepoxide in squirrel monkeys. J Pharmacol Exp Ther 224: 127-134.

Tenn CC, Fletcher PJ, Kapur S (2003). Amphetamine-sensitized animals show a sensorimotor gating and neurochemical abnormality similar to that of Schizophrenia. Schizophr Res 64: 103-114.

Tenn CC, Kapur S, Fletcher PJ (2005). Sensitization to amphetamine, but not phencyclidine, disrupts prepulse inhibition and latent inhibition. Psychopharmacology (Berl) 180: 366-376.

Van der Heyden JA, Bradford LD (1988). A rapidly acquired oneway conditioned avoidance procedure in rats as a primary screening test for antipsychotics: influence of shock intensity on avoidance performance. Behav Brain Res 31: 61-67.

Wadenberg ML, Hicks PB (1999). The conditioned avoidance response test re-evaluated: is it a sensitive test for the detection of potentially atypical antipsychotics? Neurosci Biobehav Rev 23: 851-862.

Wise RA (2004). Dopamine, learning and motivation. Nat Rev Neurosci 5: 483-494.

Xu X, Domino EF (1994). Phencyclidine-induced behavioral sensitization. Pharmacol Biochem Behav 47: 60. 